\title{
Morphology of Ulnar Nerve and its Variation in North Indian Population
}

\author{
Seema Tabassum ${ }^{1}$, N. B. Singh ${ }^{2}$, S. K. Karn ${ }^{1}$ \\ ${ }^{1}$ Associate Professor, Department of Anatomy, Darbhanga Medical College, Laheriasarai, Darbhanga, ${ }^{2}$ M.S. Anatomy, Professor \& Head, Department of \\ Anatomy, Darbhanga Medical College, Laheriasarai, Darbhanga.
}

\section{Abstract}

Introduction: The ulnar nerve is formed from medial cord of the brachial plexus. It lies medial to axillary and brachial artery as far as middle of humerus, and then pierces the medial inter muscular septum to descend on the anterior face of triceps. Lesions of the associated structures often occur. There is anatomical variations in course of ulnar nerve amongst the races. Aim: This study was conducted to analyse the anatomical variation of ulnar nerve in north Indian population. Subjects and Methods: The study was done on 30 human cadavers at Departments of Anatomy, Darbhanga Medical College and Hospital, Laheriasarai. Results: The observations showed thatUlnar nerve was present in all specimens, and in $97 \%$ cases originated from the medial cord of the brachial plexus, at the level of tip of the acromion processes and showed the normal course. Conclusion: The awareness of these variations along the normal pattern are helpful for the interventional radiologists, orthopaedicians and neurologists in preventing untoward iatrogenic injury to the ulnar nerve during radiological procedures or operating on fractured patients or diagnostic therapy.

Keywords: Ulnar Nerve, Axilla, Arm, Morphology, Cadaver, Variations, Median Nerve.

Corresponding Author: Dr. Seema Tabassum, Associate Professor, Department of Anatomy, Darbhanga Medical College, Laheriasarai, Darbhanga.

Received: July 2019

Accepted: July 2019

\section{Introduction}

The ulnar nerve is formed from medial cord of the brachial plexus. It lies medial to axillary and brachial artery as far as middle of humerus, and then pierces the medial inter muscular septum to descend on the anterior face of triceps. It passes behind the medial epicondyle to enter the forearm. Here it descends beneath flexor carpi ulnaris until this muscle thins out into tendon, leaving nerve to lie superficially on its radial side. About 2 inches above the wrist, a dorsal cutaneous branch passes deep to flexor carpi ulnaris to supply the dorsal aspects of the ulnar 1.5 fingers and the dorsal aspect of the ulnar side of the hand. Ulnar nerve crosses flexor retinaculum superficially to break up into a superficial terminal branch, supplying the ulnar 1.5 fingers, and a deep terminal branch which supplies hypothenar muscles and intrinsic muscles of hand.

The ulnar nerve is known to susceptible to entrapent on the medial side of the elbow. There are four sites where the ulnar nerve can be trapped: the arcade of Struthers, the ulnar groove, cubital tunnel, and the exit between the two heads of flexor carpi ulnaris. In particular, cubital tunnel is a wellknown location for entrapment, being the second most common site for nerve entrapment in the upper extremity after the carpal tunnel.

Lesions of the ulnar nerve occur behind the medial epicondyle \& in the cubital tunnel. When muscles are affected due to ulnar nerve dysfunction, there is ulnar neuropathy at the shoulder, arm \& elbow.

Although many studies have reported anatomical variations of the ulnar nerve, in most cases, they pertain specific racial or ethnic group. Studies on north Indian population in this regard is sparse. Therefore this study was conducted to analyse the anatomical variation of ulnar nerve in north Indian population.

\section{Subjects and Methods}

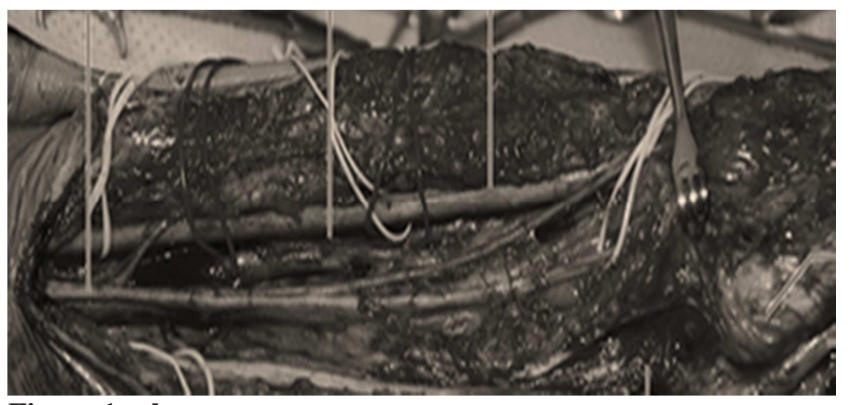

Figure 1: ulnar nerve

The study was conducted at Darbhanga Medical College and Hospital, Laheriasarai. The study was approved by institutional research committee. The study was done on 30 


\section{Tahassum et al; Marphalagy of Ulnar Nerue}

human cadavers (15 right \& 15 left) of both sexes from Departments of Anatomy, Darbhanga Medical College and Hospital, Laheriasarai. The upper limbs were dissected according to guidelines given in the Cunningham practical manual. The axilla was dissected accordingly, its contents were traced $\&$ identified. The presence or absence of ulnar nerve was noted, source of origin of ulnar nerve, its level of origin recorded with tip of acromion as bony point of reference, relation with neighbouring structures \& its course \& distribution till cubital fossa were observed. All its branches were identified. Intercommunication between the ulnar nerve and median nerve were looked for.

\section{Results}

The observations that were made are:

1. Presence of ulnar nerve: Ulnar nerve was present in all 20 upper limb specimens $(100 \%)$.

2. Source of origin: Ulnar nerve originated from the medial cord of the brachial plexus in $97 \%$ cases. In $3 \%$ case, the ulnar nerve received $\mathrm{C} 7$ fibers from lateral cord i.e. the lateral root of the median nerve and then later fused with the median root of the median nerve.

3. Level of origin: $97 \%$ ulnar nerve took origin from the tip of the acromion processes. In $3 \%$ case it took origin from distal to the tip of the acromion process.

4. Course of ulnar nerve: $97 \%$ specimens showed the normal course, i.e. medial to axillary \& brachial artery. 3 $\%$ case showed ulnar nerve present anterior to the third part of the axillary artery and brachial artery. In the midarm it passed medially as a normal course, then runs distally through the cubital tunnel.

\section{Discussion}

The ulnar nerve is in its vulnerable position behind the medial epicondyle of the humerus, may be damaged in fractures or dislocations of the elbow; it is also frequently divided in lacerations of the wrist. In the later case, all the intrinsic muscles of the fingers (apart from the radial two lumbricals) are paralysed so that the hand assumes the clawed position already described under Klumpke's palsy. The clawing is slightly less intense in the 2nd and 3rd digits because of their intact lumbricals, supplied by the median nerve. In late cases, wasting of the interossei is readily seen on inspecting the dorsum of the hand. Sensory loss over the ulnar 11/2 fingers is present. If the nerve is injured at the elbow, the flexor digitorum profundus to the 4th and 5th fingers is paralysed so that the clawing of these two fingers is less intense than in division at the wrist. Paralysis of the flexor carpi ulnaris results in a tendency to radial deviation of the wrist. Division of the ulnar nerve leaves a surprisingly efficient hand. The long flexors enable a good grip to be taken; the thumb, apart from loss of adductor pollicis, is intact and sensation over the palm of the hand is largely maintained. Indeed, it may be difficult to determine clinically with certainty that the nerve is injured; a reliable test is loss of ability to adduct and abduct the fingers with the hand laid flat, palm downwards on the table; this eliminates 'trick' movements of adduction and abduction of the fingers brought about as part of their flexion and extension respectively.

Typically the ulnar nerve can be compressed in the Cubital tunnel, formed by the tendinous arch connecting the two heads of flexor carpi ulnaris at their humeral and ulnar attachments. Other local causes of compression and neuritis at this site include trauma, inflammatory arthritis, compression by the medial head of the triceps, osteophytes, recurrent subluxation of the nerve across the medial epicondyle of the humerus and abnormal muscular variants such as the anconeus epitrochlearis.

The symptoms are pain at the medial aspect of the proximal forearm together with paraesthesia and numbness of the little finger and ulnar half of the ring finger and the ulnar side of the dorsum of the hand. These symptoms are typically worse on forced elbow flexion. There may also be associated weakness of the muscles of the forearm and the intrinsic muscles of the hand innervated by the ulnar nerve. Interestingly, flexor carpi ulnaris and profundus to the ring and little fingers are frequently spared, presumably because the fascicles supplying these muscles are located on the deep aspect of the nerve. Clawing of the hand is therefore unusual in this syndrome. Surgical treatment involves decompression of the tunnel by division of the aponeurosis of flexor carpi ulnaris with or without subsequent anterior transposition of the ulnar nerve.

Two processes account for most instances of ulnar neuropathy at the elbow: compression in the retroepicondylar groove, and compression by the humeroulnar aponeurotic arcade joining the two heads of the flexor carpi ulnaris. While conventional electrodiagnostic criteria may localize an ulnar neuropathy to the elbow, separating retroepicondylar compression from humeroulnar arcade compression is more difficult.

\section{Conclusion}

The awareness of these variations along the normal pattern are helpful for the interventional radiologists, orthopaedicians and neurologists in preventing untoward iatrogenic injury to the ulnar nerve during radiological procedures or operating on fractured patients or diagnostic therapy.

\section{References}

1. Ellis Harold in Clinical Anatomy, 11th edition, Blackwell publishing 2006.p. 198 -200

2. Richard S Snell in Clinical Anatomy by Regions, 8th edition ,Wolters Kluwer Lippincott Williams \& Wilkins; 2012 .p. 338

3. Harold Ellis, Patricia Collins, David Johnson, Eds. Gray's Anatomy: The Anatomical Basis Of Clinical Practice 39th Ed., London, Churchill Livingstone. 1999; 2024

4. Campbell WW, Pridgeon RM, Riaz G, Astruc J, Sahni KS 1991 Variations in anatomy of the ulnar nerve at the cubital tunnel: pitfalls in the diagnosis of ulnar neuropathy at the elbow. Muscle Nerve. 1991 Aug; 14(8):733-8.

5. Datta AK. Essentials of Human Anatomy, Superior and Inferior Extremities, Part III. 2nd ed. Calcutta, Chennai, Mumbai: Current Books International; 2000. p. 50-1, 101.

6. Gray H, Standring S. Gray's Anatomy, the Anatomical Basis of 


\section{Tahassum et al; Marphalagy of Ulnar Nerwe}

Clinical Practice. 41st ed. Edinburgh, London, New York, Toronto: Churchill Livingstone; 2016. p. 832, 858, 891.

7. Chaurasia BD. Human Anatomy, Upper Limb and Thorax. 7th ed., Vol. 1. Bangalore, Chennei, Kochi, Pune, Hyderabad, Mumbai, Nagpur, Patna: CBS Publishers and Distributors Pvt., Ltd.; 2016. p. $57-8$.

8. McGregor L. Synopsis of Surgical Anatomy. 12th ed. Indian Edition. Bombay: K. M. Verghese Company; 1986. p. 379-81, 385, 387.

9. Ranganathan TS. A Text Book of Human Anatomy. 6th ed. New Delhi: S. Chand \& Company (Pvt.), Ltd.; 2013. p. 53-5.

10. Romanes GJ. Cunningham's Manual of Practical Anatomy. 15th ed., Vol. 1. London: Oxford University Press; 1986. p. 33.

11. Walsh JF. The anatomy of the brachial plexus. Am J Med Sci 1877;74:387-99.

12. Kerr AT. The brachial plexus of nerve in man, the variations in its formation and branches. Am J Anat 1918;23:285-395.

13. Linell EA. The distribution of nerves in the upper limb, with reference to variabilities and their clinical signifcance. J Anat 1921;55:79-112.

14. Miller RA. Comparative studies upon the morphology and distribution of the brachial plexus. Am J Anat 1934;54:143-7.

15. Hollinshead WH. Anatomy for surgeons. In: The Back and Limbs. 1st ed., Vol. 3. New York: Harper and Row; 1966. p. 220-40.
16. Iwamoto S, Kimura K, Takahashi Y, Konishi M. Some aspects of the communicating branch between the musculocutaneous and median nerves in man. Okajimas Folia Anat Jpn 1990;67:47-52.

17. Saeed M, Rufai AA. Median and musculocutaneous nerves: Variant formation and distribution. Clin Anat 2003;16:453-7.

18. Nakatani $T$, Tanaka $S$, Mizukami $S$. Absence of the musculocutaneous nerve with innervation of coracobrachialis, biceps brachii, brachialis and the lateral border of the forearm by branches from the lateral cord of the brachial plexus. J Anat 1997; 191:459-60.

19. Chouhan R, Roy TS. Communication between the median and musculocutaneous nerve - A case report. J Anat Soc India 2002;51:72-5

20. Choi D, Rodríguez-Niedenführ M, Vázquez T, Parkin I, Sañudo JR. Patterns of connections between the musculocutaneous and median nerves in the axilla and arm. Clin Anat 2002;15:11-7.

21. Satyanarayana N, Guha R. Formation of median nerve by four roots. J Coll Med Sci 2008;5:105-7.

22. Uzun A, Seelig LL Jr. A variation in the formation of the median nerve; communicating branch between the musculocutaneous and median nerves in man. Folia Morphol (Warsz) 2001;80:99-101.

23. Meshram SW, Khobragade KJ, Pandit SV, Jadav JS. Four roots of median nerve and its surgical and clinical signifcance - A case report. Int J Anatom Variations. 2012;5:110-2.

Copyright: (ㅇ the author(s), publisher. Academia Anatomica International is an Official Publication of "Society for Health Care \& Research Development". It is an open-access article distributed under the terms of the Creative Commons Attribution Non-Commercial License, which permits unrestricted non-commercial use, distribution, and reproduction in any medium, provided the original work is properly cited.

How to cite this article: Tabassum S, Singh NB, Karn SK. Morphology of Ulnar Nerve and its Variation in North Indian Population. Acad. Anat. Int. 2019;5(2):22-24.

DOI: dx.doi.org/10.21276/aanat.2019.5.2.7

Source of Support: Nil, Conflict of Interest: None declared. 